\title{
Explicit validation of a surface shortwave radiation balance model over snow-covered complex terrain
}

\author{
N. Helbig, ${ }^{1}$ H. Löwe, ${ }^{1}$ B. Mayer, ${ }^{2}$ and M. Lehning ${ }^{1}$ \\ Received 28 January 2010; revised 15 June 2010; accepted 29 June 2010; published 23 September 2010.
}

[1] A model that computes the surface radiation balance for all sky conditions in complex terrain is presented. The spatial distribution of direct and diffuse sky radiation is determined from observations of incident global radiation, air temperature, and relative humidity at a single measurement location. Incident radiation under cloudless sky is spatially derived from a parameterization of the atmospheric transmittance. Direct and diffuse sky radiation for all sky conditions are obtained by decomposing the measured global radiation value. Spatial incident radiation values under all atmospheric conditions are computed by adjusting the spatial radiation values obtained from the parametric model with the radiation components obtained from the decomposition model at the measurement site. Topographic influences such as shading are accounted for. The radiosity approach is used to compute anisotropic terrain reflected radiation. Validations of the shortwave radiation balance model are presented in detail for a day with cloudless sky. For a day with overcast sky a first validation is presented. Validation of a section of the horizon line as well as of individual radiation components is performed with high-quality measurements. A new measurement setup was designed to determine terrain reflected radiation. There is good agreement between the measurements and the modeled terrain reflected radiation values as well as with incident radiation values. A comparison of the model with a fully three-dimensional radiative transfer Monte Carlo model is presented. That validation reveals a good agreement between modeled radiation values.

Citation: Helbig, N., H. Löwe, B. Mayer, and M. Lehning (2010), Explicit validation of a surface shortwave radiation balance model over snow-covered complex terrain, J. Geophys. Res., 115, D18113, doi:10.1029/2010JD013970.

\section{Introduction}

[2] For the computation of local surface characteristics such as soil or snowpack temperatures in complex terrain a highly detailed surface radiation balance model is necessary. Surface radiation models employ spatial values of individual radiation components to account for the impact of complex terrain. However, spatially resolved measurements of incident global radiation are usually not available for complex terrain and there is mostly a lack of measurements of individual radiation components.

[3] Two solutions are commonly applied in surface process models: parametric and decomposition models. In parametric models incident radiation components are derived from local astronomic relationships (e.g., solar zenith and azimuth angles, Earth-Sun distance), from parameterizations for the atmospheric transmittance and from a set of atmospheric

\footnotetext{
${ }^{1}$ WSL Institute for Snow and Avalanche Research SLF, Davos, Switzerland.

${ }^{2}$ Meteorological Institute, Ludwig-Maximilians University, Munich, Germany.

Copyright 2010 by the American Geophysical Union. 0148-0227/10/2010JD013970
}

parameters measured at the surface (e.g., air temperature, relative humidity) [cf. Bird and Hulstrom, 1980, 1981; Iqbal, 1983]. Gueymard and Myers [2008] showed that the Bird model of Bird and Hulstrom [1980, 1981] performs relatively well in comparison to other models and to even those that are more complex. However, atmospheric transmittances are only well defined under cloudless sky conditions. Decomposition models, on the other hand, split a measured global radiation value according to piecewise correlations for various sky conditions into direct and diffuse sky values [Liu and Jordan, 1960; Orgill and Hollands, 1977; Erbs et al., 1982; Iqbal, 1983; Reindl et al., 1990; Boland et al., 2001]. These decomposition models are statistical models which strongly depend on local conditions and which require long-term measurement series for calibration. A comprehensive statistical decomposition model that covers the climate of various geographical areas has so far not been published. Nevertheless, the advantage of decomposition models is that actual atmospheric conditions are described, i.e., they include all sky conditions.

[4] Terrain parameters dictate if a surface receives direct radiation or if it is shaded. Terrain parameters further control how much sky is visible and therefore influence incident diffuse sky radiation. The knowledge of the so-called Sunor-shadow and mutual visibility is thus important for the 
radiation balance in complex terrain. Numerous Sun-orshadow and mutual visibility algorithms exist with different levels of accuracy and amount of computation time. For the computation of Sun-or-shadow, commonly an algorithm traces a ray along the beam to the Sun in unit steps of cell lengths and compares the terrain height below the beam position to the beam height [e.g., Nunez, 1980]. These algorithms are often not very accurate and do not guarantee that each grid cell on the way to the Sun position projected on the very boundary cell is checked. Other approaches include the computation of the horizon for azimuthal intervals in order to store the horizon [e.g., Dozier and Bruno, 1981]. In this case, an accurate description of the surrounding horizon in complex terrain strongly depends on the choice of the azimuthal sectors together with the size of the model domain. In the work of Helbig et al. [2009] the fast traversal algorithm for ray tracing of Amanatides and Woo [1987] was applied to identify all grid cells along the azimuth direction of a beam to the Sun (Sun-or-shadow) or, in case of the mutual visibility algorithm, to another grid cell. The horizon is derived for each grid cell and is not stored in order to reduce memory consumption.

[5] With a detailed surface radiation balance local surface characteristics can be studied in surface process models. The presented radiation scheme has been developed as a module of Alpine3D (cf. Lehning et al. [2004, 2006] for an overview of Alpine3D) a model developed at WSL Institute for Snow and Avalanche Research SLF, Davos, Switzerland. It has successfully been applied for different purposes, with varying module focuses. The module SNOWPACK [Bartelt and Lehning, 2002; Lehning et al., 2002a, 2002b] predicts snow cover and surface characteristics such as albedo. The surface radiation balance module computes terrain reflected radiation for surfaces that are mutual visible. In the work of Helbig et al. [2009] the radiosity approach, well known in computer graphics, was introduced to study multiple, anisotropic terrain reflected radiation in complex terrain.

[6] The scope of this paper is to detail how one-band (broadband) direct and diffuse sky radiation can be computed spatially for all sky conditions in complex terrain and to compare model output with measurements and with a more sophisticated model. In section 2 we describe the theory of the radiation balance model, a compilation of the above mentioned models tailored for applications in high mountainous terrain within the European Alps. In section 3, terrain parameters are described and details regarding the Alpine3D model setup are given. Second, all measurement data for the validation and all input data are detailed. A new measurement design to determine terrain reflected radiation is presented. Furthermore, the three-dimensional radiative transfer model MYSTIC [Mayer, 2009] was used for validation, which is a more sophisticated model using the Monte Carlo (MC) technique for tracing photons on their random paths in cloudy atmospheres. In section 4 the modeled radiation as well as the Sun-or-shadow algorithm are compared to measurements. Each individual radiation component is separately validated instead of only validating total (global) radiation. Such a detailed validation is essential when the radiation balance for complex terrain is derived. To validate the model we selected one point using high-quality measurements and a new measurement setup to determine terrain reflected radiation. A discussion and conclusion is given in section 5 .

\section{Surface Radiation Balance Model}

[7] The radiation balance model was developed over several years by several contributors (a detailed review is given by Helbig [2009]). Here, the complete theory of the shortwave (SW) radiation balance model is presented. First, we introduce our parametric model for the computation of spatial radiation components under cloudless sky conditions. Second, we present a decomposition model in order to adjust the radiation components under cloudless sky with the actual atmospheric conditions considering all sky conditions.

[8] In the following we refer to incident global radiation as the broadband downwelling radiative flux at a point obtained from the hemispherically integrated downwelling radiance over the complete visible solar spectrum and measured in $\mathrm{W} \mathrm{m}{ }^{-2}$. The radiative flux at a point is always derived in the sloped coordinate system, i.e., having its $z$ axis in the direction of the surface normal. The hemispherical integral is composed of directions pointing to the sky and to the terrain. The downwelling radiance from the sky consists solely of a diffuse contribution which is isotropic and a direct solar beam contribution involving a delta function which is valid for a point-shaped Sun.

[9] Incident global radiation $S_{\mathrm{g}}$ is defined as the sum of incident direct (beam) radiation $S_{\mathrm{b}}$, incident diffuse sky radiation $S_{\mathrm{d}}$ due to scattering processes in the atmosphere, and incident radiation $S_{\mathrm{t}}$ received from the surrounding terrain, due to reflections: $S_{\mathrm{g}, i}=S_{\mathrm{b}, i}+S_{\mathrm{d}, i}+S_{\mathrm{t}, i}$. All radiation components are computed for each of the $i=1,2 \ldots, N$ rectangular surfaces or so-called patches in a digital elevation model (DEM). In the following two sections only spatially varying parameters are marked by $i$ indicating the patch. The application of the radiosity approach to compute multiple, anisotropic terrain reflections $S_{\mathrm{t}}$ in complex terrain was presented by Helbig et al. [2009].

\subsection{Parametric Model}

[10] An observation of air temperature $T_{\mathrm{a}}$, pressure $p$, and relative humidity $r h$ at one location is spatially extrapolated (details in the work of Helbig [2009]). The set is subsequently used to mimic the varying atmospheric conditions within the domain by determining a spectrally integrated atmospheric transmittance for each patch which in turn is used to compute the spatially varying transmitted radiation from the top of atmosphere $S_{\text {toa }}$ value, with $S_{\text {toa }}=$ TSI $E_{0}$. The diurnal changing dimensionless eccentricity correction factor $E_{0}$ of the orbit of the Earth is computed according to Spencer [1971]. We use a total solar irradiance TSI of $1366.1 \mathrm{~W} \mathrm{~m}^{-2}$ [cf. Fröhlich and Lean, 1998; Fröhlich, 2006].

[11] Due to scattering processes by molecules (Rayleigh scattering) and by aerosols (Mie scattering) as well as due to absorption processes by different components of the atmosphere only a fraction of $S_{\text {toa }}$ is received as global radiation at the surface even under cloudless sky conditions. Simple broadband transmittance functions for each atmospheric constituent are therefore commonly applied to $S_{\text {toa }}$ in order to obtain the spectrally integrated direct and diffuse sky radiation components. Furthermore, these transmittance functions are often assumed to be multiplicative. For the 
Bird model [Bird and Hulstrom, 1980, 1981] developed the following equation to compute incident direct radiation $S_{\mathrm{b}}$ on a plane normal to the Sun beam

$$
S_{\mathrm{b}, i}^{\perp}=0.9751 S_{\mathrm{toa}} \tau_{\mathrm{r}, i} \tau_{\mathrm{o}} \tau_{\mathrm{g}, i} \tau_{\mathrm{w}, i} \tau_{\mathrm{a}, i}
$$

where a factor of 0.9751 is used, which is based on a more recent TSI value and its spectral distribution (cf. "Parameterization Model C" of Iqbal [1983]). The broadband transmittance functions $\tau$ in equation (1) are taken from Bird and Hulstrom [1981] and account for Rayleigh-scattering $\left(\tau_{\mathrm{r}}\right)$, for absorption by uniformly mixed gases such as $\mathrm{CO}_{2}$ and $\mathrm{O}_{2}\left(\tau_{\mathrm{g}}\right)$, for absorption by ozone $\left(\tau_{\mathrm{o}}\right)$, for absorption by water vapor $\left(\tau_{\mathrm{w}}\right)$ and for Mie scattering as well as absorption by aerosols $\left(\tau_{\mathrm{a}}\right)$. In some equations of the transmittance functions, constant or calculated parameters were used, which vary from those presented by Bird and Hulstrom [1981] or Iqbal [1983]. A detailed description is given by Helbig [2009] and is not repeated here to keep the focus on the model structure.

[12] Equation (1) was further extended by introducing a correction $b$ (in $\mathrm{m}$ ) for the altitude dependence of the total transmittance at each point [Bintanja, 1996; Corripio, 2002]

$$
\begin{aligned}
& b_{i}=2.210^{-5} \cdot z_{i} \quad \text { for } \quad z_{i} \leq 3000 \mathrm{~m} \\
& b_{i}=2 \cdot 210^{-5} \cdot 3000 \mathrm{~m} \text { for } \quad z_{i}>3000 \mathrm{~m}
\end{aligned}
$$

where $z_{i}$ is the elevation in the discrete DEM. With the given modifications for direct radiation under cloudless sky incident on arbitrary tilted surfaces (by inclusion of $\cos \theta_{\mathrm{i}}$ ) equation (1) becomes

$$
S_{\mathrm{b}, i}^{\text {cloudless }}=0.9751 S_{\mathrm{toa}} \cos \theta_{i} \chi_{\mathrm{sun}, i}\left(\tau_{\mathrm{r}, i} \tau_{\mathrm{o}} \tau_{\mathrm{g}, i} \tau_{\mathrm{w}, i} \tau_{\mathrm{a}, i}+b_{i}\right) .
$$

Equation (3) includes the Sun-or-shadow function $\chi_{\mathrm{sun}, i}$, which equals one if the center of a patch at $i$ is in the Sun, and zero if it is in shadow. The angle $\theta_{i}$ is the local incidence angle on a tilted surface, i.e., the angle between the Sun vector and the surface normal. For a horizontal surface $\theta_{i}$ equals the zenith angle $\theta_{\mathrm{z}}$. Equation (3) constitutes our model for direct beam SW radiation for cloudless sky conditions (indicated by "cloudless").

[13] Our model for incident diffuse sky radiation $S_{\mathrm{d}}$ under cloudless sky conditions is given by Iqbal [1983]:

$$
S_{\mathrm{d}, i}^{\text {cloudless }}=\left(S_{\mathrm{d}, i}^{\text {Rayl. }}+S_{\mathrm{d}, i}^{\mathrm{Mie}}+S_{\mathrm{d}, i}^{\text {mult.refl. }}\right) F_{\mathrm{sky}, i} \text {. }
$$

Here, the fraction of visible sky is accounted for by the sky view factor $F_{\text {sky }}$, which is the ratio of the flux received by an inclined surface from the visible part of the sky to the flux from a theoretical unobstructed hemisphere. We compute the sky view factor $F_{\text {sky }, i}$ from the sum of terrain view factors applying the normalization property of view factors (for details see Helbig et al. [2009]). All three components, namely $S_{\mathrm{d}, i}^{\text {Rayl. }}$, diffuse sky radiation due to Rayleigh-scattering after the first pass through the atmosphere, $S_{\mathrm{d}, i}^{\text {Mie }}$, diffuse sky radiation due to Mie-scattering, and $S_{\mathrm{d}, i}^{\text {mult.refl., }}$, diffuse sky radiation due to multiple reflections between the ground and the atmosphere, are computed according to Iqbal [1983]. All diffuse sky radiation fluxes are parameterized with broadband transmittance functions as described for the computation of direct radiation under cloudless sky. However, a transmittance function due to Mie-scattering $\tau$ as and aerosol absorption $\tau_{\text {aa }}$ is required separately. According to Bird and Hulstrom [1981] they are related via $\tau_{\mathrm{a}, i}=\tau_{\mathrm{aa}, i} \tau_{\mathrm{as}, i}$. Both transmittance functions, $\tau_{\mathrm{aa}}$ and $\tau_{\mathrm{a}}$, are computed according to Bird and Hulstrom [1981].

\subsection{Decomposition Model}

[14] Cloudless sky conditions insufficiently describe the variety of real atmospheric conditions. However, the determination of atmospheric transmittances for cloudy sky conditions is hardly feasible, since this would require detailed information of clouds, e.g., cloud cover, optical thickness, or position. Even in case of cloudless sky, different levels of humidity, atmospheric composition or aerosols occur, which also alter the parameterized mean atmospheric transmittance for cloudless sky conditions. Though this detailed information is usually not available, as a result, a decomposition model is applied to obtain direct and diffuse sky radiation from one measured global radiation value for all sky conditions.

[15] Decomposition models are constructed by means of piecewise fitting measured values of the diffuse sky fraction $M_{\mathrm{d}}=S_{\mathrm{d}}^{\text {allsky }} / S_{\mathrm{g}}^{\text {allsky }}$ and the clearness index $M_{\mathrm{t}}=S_{\mathrm{g}}^{\text {allsky }} / S_{\text {toa }}$ $\cos \theta_{\mathrm{z}}$ with the diffuse sky radiation $S_{\mathrm{d}}^{\text {allsky }}$ and the global radiation $S_{\mathrm{g}}^{\text {allsky }}$ under all sky conditions including cloudless as well as cloudy. A typical approach to retrieve the diffuse sky fraction $M_{\mathrm{d}}$ from the observed all sky global radiation (here converted to clearness index $M_{\mathrm{t}}$ ) is to separate the observations into three classes (cloudless sky, partly cloudcovered sky, and cloudy sky) and to establish an empirical relationship for each of these classes from a large set of observations. A well-known model is that from Erbs et al. [1982]. It is based on data of measurement stations with a wide range of altitudes but only includes latitudes from $31^{\circ} \mathrm{N}$ to $42^{\circ} \mathrm{N}$ and longitudes from $-72^{\circ} \mathrm{E}$ to $-122^{\circ} \mathrm{E}$, which does not comprise the Eastern Swiss Alps. However, since the model of Erbs et al. [1982] is a well-known decomposition model and since it was developed based on data measured at larger altitudes where cleaner atmospheres occur, such as at high locations in the Swiss Alps, we chose their model for comparison.

[16] Even though plenty of decomposition models have been published, no decomposition model exists for the climate of the Eastern Swiss Alps. We selected a model, which also included solar elevation within the correlation, and corresponded best to the Eastern Swiss Alps. This resulted in a combination of two decomposition models proposed by Reindl et al. [1990]. For a partly cloud-covered sky the solar zenith angle is taken into account whereas under cloudy sky the dependency on the solar zenith angle is assumed to be low and is neglected. Very often, only a small data set or only extremely scattered data for $M_{\mathrm{d}}$ are found in literature for clearness indices $M_{\mathrm{t}}$ larger than 0.8 . This is probably due to the lack of data at high elevations where the atmosphere is clean and dry resulting in larger clearness indices $M_{\mathrm{t}}$. Therefore, for cloudless sky conditions a constant value of $M_{\mathrm{d}}=0.147$ as proposed by one model of Reindl et al. [1990] was chosen. Our combination of Reindl et al.'s [1990] models is as follows

$$
\begin{aligned}
0 \leq M_{t} \leq 0.3: M_{\mathrm{d}}= & 1.020-0.248 M_{\mathrm{t}} \\
& \text { and } M_{\mathrm{d}} \leq 1.0 \\
0.3<M_{\mathrm{t}}<0.78: M_{\mathrm{d}}= & 1.400-1.749 M_{\mathrm{t}}+0.177 \sin \left(\pi / 2-\theta_{\mathrm{z}}\right) \\
& \text { and } M_{\mathrm{d}} \leq 0.97 \text { and } M_{\mathrm{d}} \geq 0.1 \\
M_{t} \geq 0.78: M_{\mathrm{d}}= & 0.147 .
\end{aligned}
$$




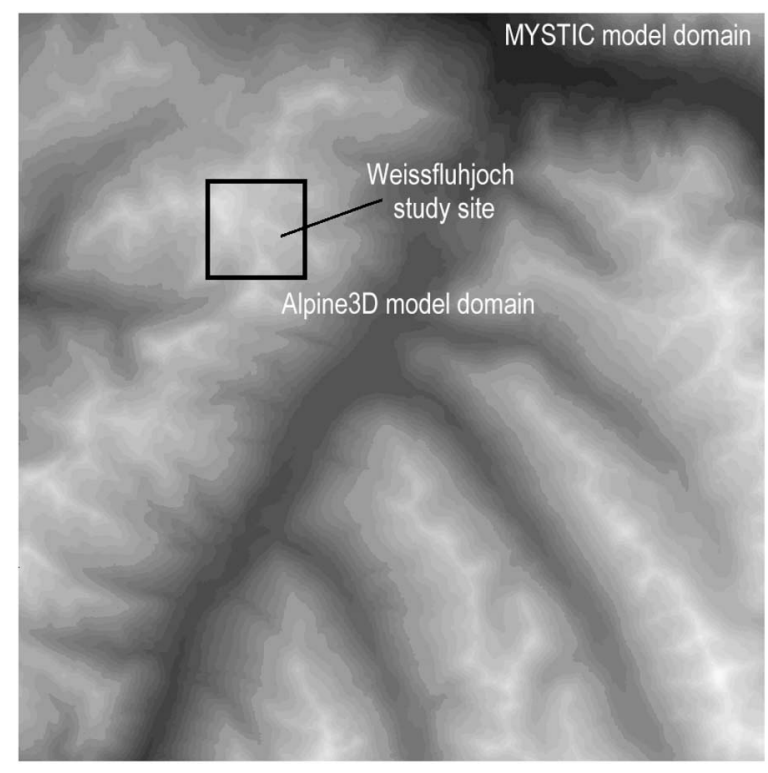

Figure 1. The DEM of the smaller Alpine3D model domain is shown within the DEM of the large MYSTIC model domain around the Weissfluhjoch study site. Within the DEM the heights vary between the minimum of $1100 \mathrm{~m}$ (black) and the maximum of $3150 \mathrm{~m}$ (white). The location of the Weissfluhjoch study site is indicated.

In practice, the clearness index $M_{\mathrm{t}}$ is computed from a global radiation value $S_{\mathrm{g}}^{\text {meas }}$ measured at an exposed location (i.e., $\left.F_{\text {sky }} \approx 1\right)$ under all sky conditions by $M_{\mathrm{t}}=S_{\mathrm{g}}^{\text {meas }} / S_{\text {toa }} \cos \theta_{\mathrm{z}}$. By means of equation (5) this is converted to a diffuse sky fraction $M_{\mathrm{d}}$. Together with $S_{\mathrm{g}}^{\text {meas }}$ the diffuse sky radiation $S_{\mathrm{d}}^{\text {allsky }}$ is subsequently derived from $M_{\mathrm{d}}=S_{\mathrm{d}}^{\text {allsky }} / S_{\mathrm{g}}^{\text {meas }}$ at the measurement point.

[17] The decomposition model of equation (5) provides radiation components $S_{\mathrm{b}}^{\text {allsky }}$ and $S_{\mathrm{d}}^{\text {allsky }}$ for locations where an exposed measured value of global radiation is available. However, in order to obtain $S_{\mathrm{b}}^{\text {allsky }}$ and $S_{\mathrm{d}}^{\text {allsky }}$ for locations where no measured values are available we adjust our spatial incident radiation components derived for cloudless sky conditions $S_{\mathrm{b}}^{\text {cloudless }}$ and $S_{\mathrm{d}}^{\text {cloudless }}$, cf. equations (3) and (4), with the actual atmospheric conditions obtained from the diffuse sky ratio $M_{\mathrm{d}}$ (equation (5)). For this, two adjustment coefficients are introduced at the measurement station, namely $\mathrm{c}_{\mathrm{b}}$

$$
\mathrm{c}_{\mathrm{b}}=\frac{S_{\mathrm{g}}^{\text {meas }}\left(1-M_{\mathrm{d}}\right)}{S_{\mathrm{b}}^{\text {cloudless }}}
$$

and $\mathrm{c}_{\mathrm{d}}$

$$
\mathrm{c}_{\mathrm{d}}=\frac{S_{\mathrm{g}}^{\text {meas }} M_{\mathrm{d}}}{S_{\mathrm{d}}^{\text {cloudless }}} .
$$

The radiation components at each patch (i.e., the spatial distribution) under all sky conditions $S_{\mathrm{b}, i}^{\text {allsky }}$ and $S_{\mathrm{d}, i}^{\text {allky }}$ are thus computed according to the diffuse sky ratio at the measurement station, i.e., $S_{b, i}^{\text {allsky }}=\mathrm{c}_{\mathrm{b}} S_{\mathrm{b}, i}^{\text {cloudless }}$ and $S_{\mathrm{d}, i}^{\text {allsky }}=$ $\mathrm{c}_{\mathrm{d}} S_{\mathrm{d}, i}^{\text {cloudless. }}$. Equations (3)-(7) constitute our model to compute spatial incident direct and diffuse sky radiation for all atmospheric conditions. In order to differentiate it from
Reindl's models it is from now on called "Reindl*." In the following we do not refer to $S_{\mathrm{b}}^{\text {cloudless }}, S_{\mathrm{b}}^{\text {allsky }}$ or $S_{\mathrm{d}}^{\text {cloudless }}$ and $S_{\mathrm{d}}^{\text {allsky }}$ but we only use $S_{\mathrm{b}}$ and $S_{\mathrm{d}}$.

\section{Data}

\subsection{Terrain Parameter}

[18] A DEM is a discretization of the real, continuous surface height $z(x, y)$, here it is given as an array of terrain elevations $z_{i}$ with $i=0,1 . . N$ in a square domain of size $L$ with a given horizontal resolution $\Delta x=\Delta y$. We use a DEM from Federal Office of Topography (Swisstopo, http://www. swisstopo.ch/en/), with 100x100 square planar grid cells of size $\Delta x=\Delta y=25 \mathrm{~m}$ (cf. Alpine3D domain in Figure 1), and a mean height accuracy for the European Alps of $3 \mathrm{~m}$. The height $z_{i}$ is assigned to the center of the grid cell $i$. In order to enable the representation of steep ridges in model domains, the extraction method of terrain parameters of Corripio [2002] was applied, which divides a rectangle grid cell into two triangles and computes an average of the resulting two surface normal vectors.

[19] In complex terrain and in model domains with high resolutions the knowledge of Sun-or-shadow as well as mutual visibility is especially important. Since mutual visibility determines if two surface patches can actually exchange radiation and Sun-or-shadow determines if a patch actually receives direct radiation, an accurate implementation of an algorithm to derive both was one important objective for the radiation model. The method to determine mutual visibility between patches as well as the method to detect Sun-or-shadow for each patch are described in the work of Helbig et al. [2009]. Mutual visibility is determined between individual patches instead of a simplified azimuthal sector method. Each intermediate patch is involved in the algorithm that checks for mutual visibility. For this the horizontal stepwise search path of Amanatides and Woo [1987] was implemented.

\subsection{Model Setup}

[20] An Alpine3D model run was set up starting from 1 October 2006 up to the validation days in order to simulate a realistic, spatially inhomogeneous snow and albedo distribution for the validation period. Snow surface and canopy albedo values are computed in SNOWPACK at each time step for each patch. Constant snow free surface albedo values are assigned to each land use class. In the surroundings of the Weissfluhjoch study site bare rock is the dominant land use class. Other important land use classes in the model domain are bare soil and subalpine meadow which have differing albedo values.

[21] For the validation of the model with data from an elevated horizontally mounted instrument site we introduced a virtual plane in the model domain atop of the corresponding grid cell. This virtual plane is a horizontal level patch that accounts for the actual height of the measuring instruments and differs from the DEM surface elevation of the corresponding patch. It can be introduced on arbitrary patches in the model domain. In the case of the measurement site at the roof of the long hut at the Weissfluhjoch study site (black circle (P) in Figure 2) the virtual plane was $3.06 \mathrm{~m}$ above the DEM height, resulting in a measurement height of $2543.16 \mathrm{~m}$ 


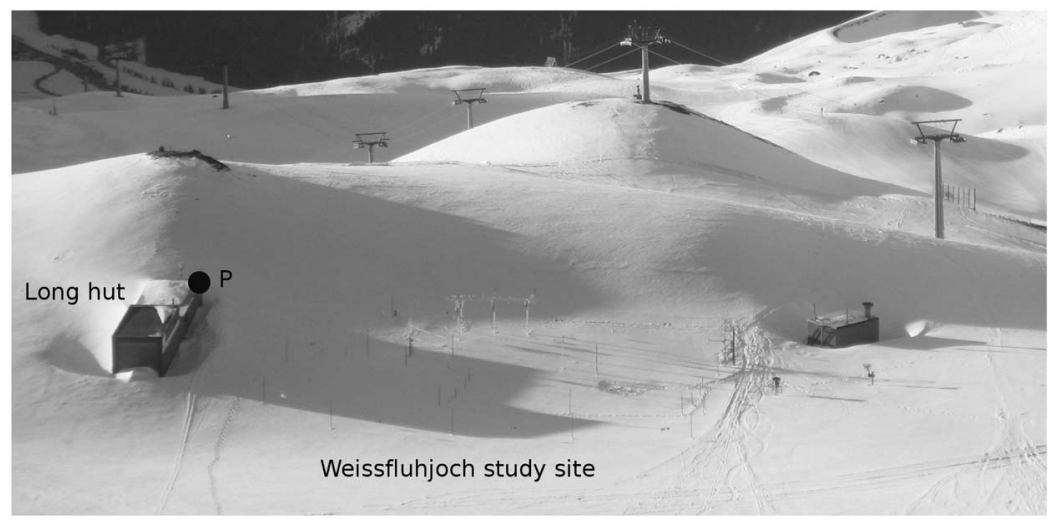

Figure 2. Picture of local shading within the Weissfluhjoch study site, taken in the morning in March (N. Helbig). P, location of the SW radiation measurement point.

at the measurement point (Swiss National Coordinates: East: 780892, North: 189235).

\subsection{Measurements of Horizon Angles}

[22] For the validation of the Sun-or-shadow and mutual visibility detection algorithm, a section of the horizon line (i.e., horizon angles within a certain azimuth angle interval) was measured as seen from the roof of the long hut at the Weissfluhjoch study site. The steep east-facing slope (Figure 3, top) was scanned by means of a Leica TCRP1202 tachymeter (Leica Geosystems, http://www.leica-geosystems. com/corporate/en/lgs_4547.htm) with an accuracy of $0.00054^{\circ}$. In addition, the horizon line was extracted by digital image analysis from a panorama picture of "Atlas der Schweiz" (http://www.atlasderschweiz.ch).

\subsection{Measurements of Meteorological Values}

[23] At the measurement site Weissfluhjoch above Davos (Switzerland) at $2540 \mathrm{~m}$ a.s.l. various radiation measurements are recorded and were used as verification data for the model. Incident SW radiation, direct $S_{\mathrm{b}}$ and diffuse sky radiation $S_{\mathrm{d}}$ are permanently measured by the Physikalisch Meterologisches Observatorium and World Radiation Center (PMOD/WRC, http://www.pmodwrc.ch) on the long hut. Diffuse sky radiation is measured by a Kipp \& Zonen CM21 Pyranometer mounted on a Sun tracker with a shading device for the Sun. Direct radiation is measured by a Kipp \& Zonen CH1 Pyrheliometer mounted on a Sun tracker.

[24] The single set of meteorological values and the single global radiation value required for the computation of spatial incident radiation were obtained from an exposed meteorological measurement station located at Weissfluhjoch at $2693 \mathrm{~m}$ a.s.l. All meteorological input data as well as all verification data were averaged to obtain hourly mean values.

\subsection{Measurement of Terrain Reflected Radiation}

[25] A thorough validation of the modeled reflected radiation from the surrounding terrain would require a measurement device which is capable of (1) masking the solid angle of the pyranometer hemisphere which is exposed to the sky and (2) separating radiation originating from the terrain from that originating from the intermediate atmosphere. However, no such measurements have been reported in literature yet. Since (2) poses, if even feasible, a major technical challenge in order to separate both components and since the atmospheric contribution is assumed to be negligible at the high elevations considered here, a simpler experimental setup is proposed in the following which tries to meet (1) as close as possible.

[26] We constructed a removable black cardboard horizon around a CM21 pyranometer (PMOD/WRC, http:/www. pmodwrc.ch) (Figure 4) to measure relative values of terrain reflected radiation at the Weissfluhjoch study site. Note that even though the terrain view factor is only $3 \%\left(1-F_{\text {sky }} \approx\right.$ 0.03 ) at the measurement point this appeared to be accurately predicted by the modeled terrain radiation. The location was
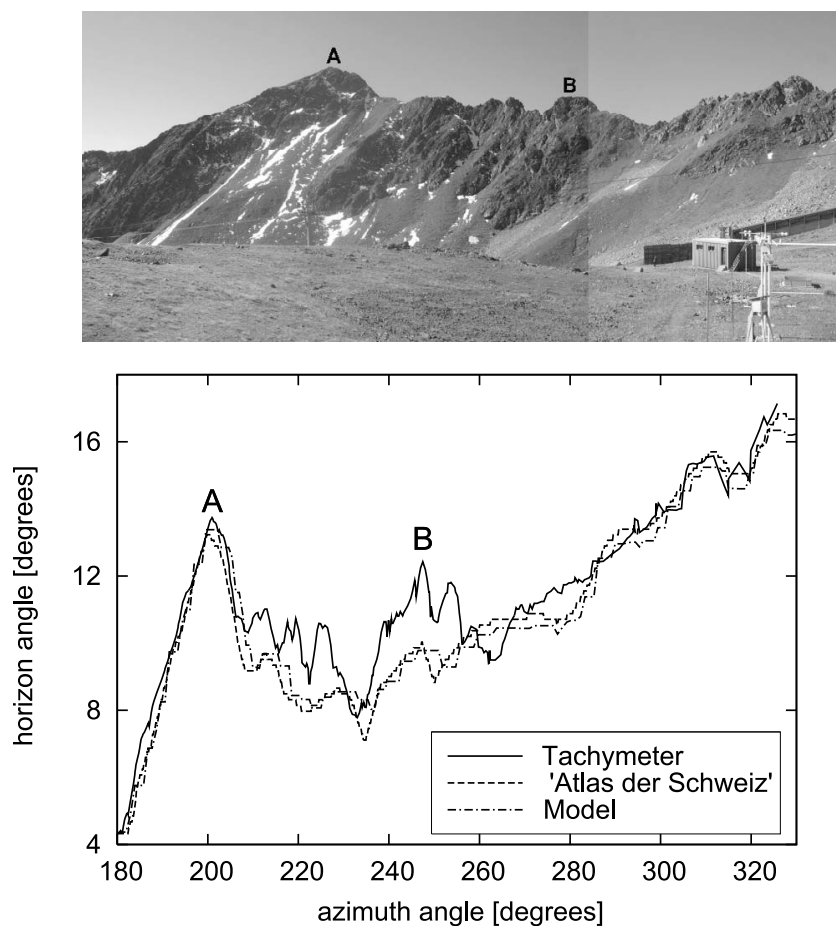

Figure 3. (top) Picture of the east-facing slope as seen from the measurement point at the Weissfluhjoch study site (N. Helbig). (bottom) Horizon angles as a function of azimuth angles. 


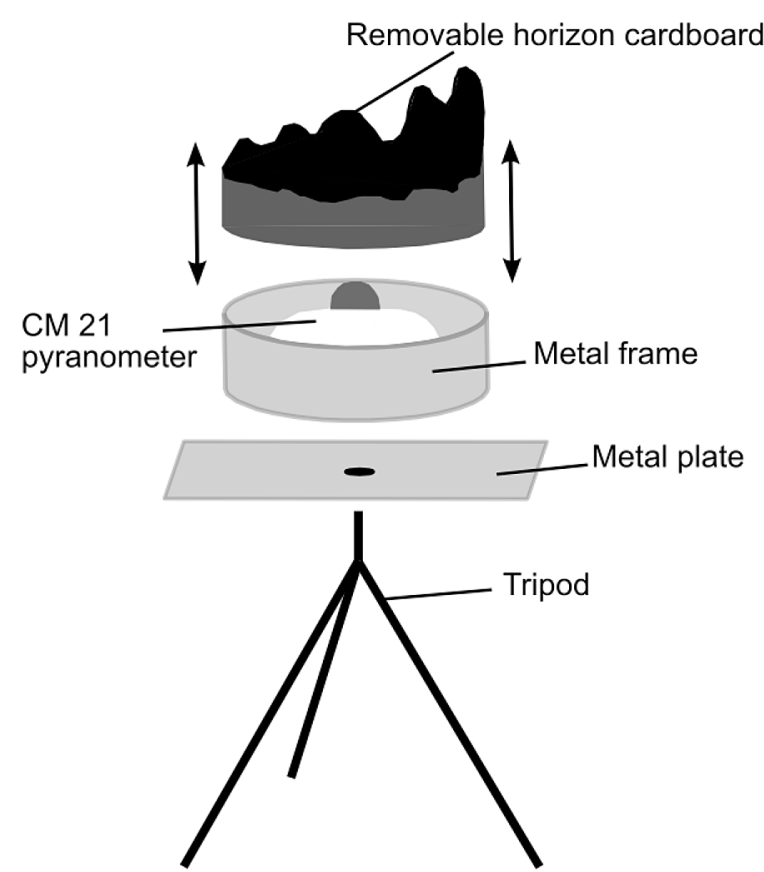

Figure 4. Schematic of the removable horizon device around a pyranometer for measuring relative values of terrain reflected radiation $S_{\mathrm{t}}$ including a black cardboard horizon, a metal frame and plate, a CM21 pyranometer, and a tripod.

primarily dictated by the availability of high-quality measurements already available at this site as well as due to the easy accessibility of the study site. The horizon line of the black cardboard horizon (with $\alpha$ usually lower than 0.1 ) was extracted from a panorama picture produced with "Atlas der Schweiz" (http://www.atlasderschweiz.ch) which is based on the $25 \mathrm{~m} \mathrm{DEM}$ of Swisstopo (http://www.swisstopo.ch/en/). The instrument was mounted on a tripod beside the permanent measurement instruments on the roof of the long hut (black circle (P) in Figure 2). Masking and unmasking the terrain in 14 minute intervals provided terrain reflected radiation values. Measurements were conducted every second and were averaged over two minutes. Only six values from 12 minute intervals were used for comparisons with modeled radiation values since after 12 minutes the removable cardboard horizon had to be mounted or unmounted on the device.

[27] For comparison two days with approximately the same Sun position and similar atmosphere composition (cloudless sky day) but one with snow (winter) and one without snow (summer) on the ground were selected.

[28] A constant number of $N=10000$ terrain reflections was applied for the modeling of terrain reflected radiation with the radiosity approach implemented in the surface radiation balance model.

\subsection{Monte Carlo Model MYSTIC}

[29] The Monte Carlo code for the phYSically correct Tracing of Photons In Cloudy atmospheres (MYSTIC) [Mayer, 2009] is a three-dimensional radiative transfer model accounting for three-dimensional inhomogeneous atmospheres, two-dimensional surface albedo distributions, and topography. MYSTIC traces photons through the atmosphere along their random paths simulating each interaction by sampling randomly from the respective probability distributions, e.g., the respective scattering phase function when the photon is scattered by a molecule, aerosol particle, cloud droplet, or ice particle. In contrast to all other three-dimensional radiative transfer methods the $\mathrm{MC}$ method does not require any further simplifications. Within the uncertainty determined by the statistical MC noise the result can be considered correct for the given input conditions. MYSTIC has been extensively validated by comparison with other three-dimensional radiative transfer codes [Cahalan et al., 2005] and by comparison with observations [Emde and Mayer, 2007]. A detailed description of the implementation of topography and a validation with experimental data was recently provided by Mayer et al. [2010].

[30] For this application we used the backward MC technique which allows reasonably fast and accurate radiation calculations for some locations in a large model domain [Mayer, 2009; Emde and Mayer, 2007]. To make sure that all effects of the surrounding mountains were properly included, a model domain of $700 \times 700$ grid cells with grid cells of $\Delta x=$ $\Delta y=25 \mathrm{~m}$ was chosen, including the Alpine3D domain with 100x100 grid cells (see Figure 1). The elevation data were also taken from Swisstopo (http://www.swisstopo.ch/en/). Direct, diffuse downward, and diffuse upward radiation was calculated for the $24 \times 31$ grid cells around the Weissfluhjoch study site (see Figure 1). 100,000 photons were run for each grid cell to obtain low-noise results. For the calculation the midlatitude summer atmosphere by Anderson et al. [1986] was used. A default aerosol according to Shettle [1989] was used which is a rural aerosol with a horizontal visibility of $50 \mathrm{~km}$ at sea level. The surface albedo distribution predicted by Alpine3D was used as input to MYSTIC. Outside the Alpine3D domain a constant mean albedo value of 0.6 was assumed. Broadband solar radiation was calculated using the accurate correlated-k distribution by Kato et al. [1999] with 32 spectral bands between 0.25 and $4.5 \mu \mathrm{m}$.

\section{Results}

\subsection{Validation With Measurements}

\subsubsection{Sun-or-Shadow Algorithm}

[31] In Figure 3 (bottom) scanned horizon angles are compared to those extracted from a panorama picture of "Atlas der Schweiz" and to those modeled with the algorithm presented by Helbig et al. [2009]. Horizon angles are depicted as a function of azimuth angles for the chosen section of the horizon line. For comparison right above in Figure 3 (top) the steep east-facing slope is shown as seen from the measurement point indicated in Figure 2 by the black circle and the $(\mathrm{P})$.

[32] The modeled horizon angles follow the angles extracted from "Atlas der Schweiz" well. A maximum error of approximately one degree occurs at an azimuth angle of about $235^{\circ}$. Overall, the scanned horizon angles match the angles of both other methods well. However, for azimuth angles from $206^{\circ}$ to $285^{\circ}$ the scanned values are larger, up to $2.5^{\circ}$. Here it is obvious that the resolution of the DEM $(25 \mathrm{~m})$ is not fine enough to capture all details. For a mean 

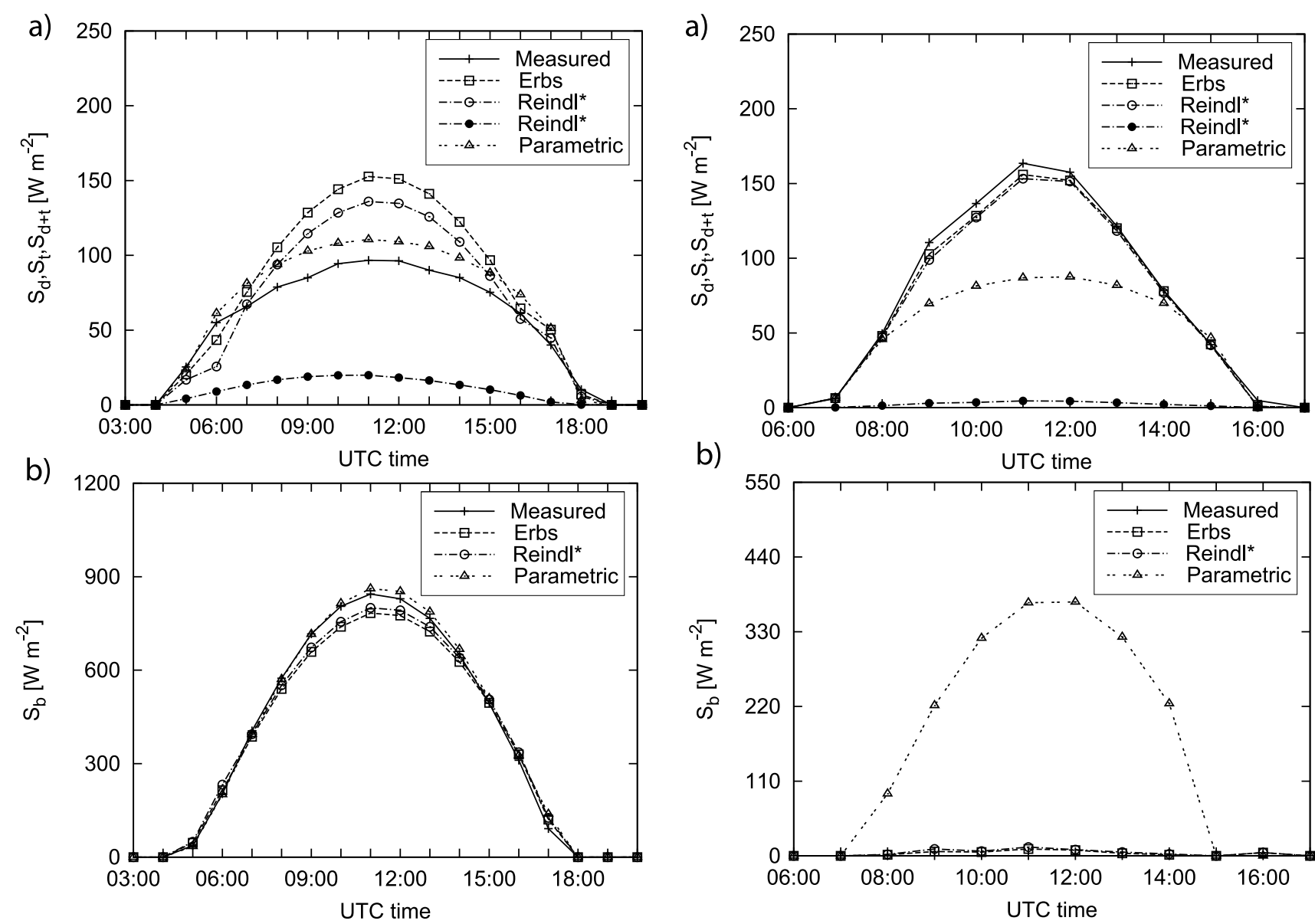

Figure 5. Comparison of measured and modeled radiation values on 20 April 2007 at Weissfluhjoch study site. Modeled values come from the decomposition model of Erbs et al. [1982] (Erbs), our Reindl* model as in equations (3)-(7) (Reindl*), and the parametric model as given by equations (3) and (4) (Parametric). (a) Plus signs indicate measured total diffuse radiation $\left(S_{\mathrm{d}}+S_{\mathrm{t}}\right)$, unfilled signs diffuse sky radiation $S_{\mathrm{d}}$, and filled circles terrain reflected radiation $S_{\mathrm{t}}$. (b) Direct radiation $S_{\mathrm{b}}$ is shown.

Figure 7. Same as in Figure 5 but for 22 January 2007, a day with overcast sky.

horizontal distance of $413 \mathrm{~m}$ an angle difference of $2.5^{\circ}$ corresponds to a height difference of only $18 \mathrm{~m}$.

\subsubsection{Direct and Diffuse Sky Radiation}

[33] Here, we present validations for two opposite sky conditions. In Figures 5 and 6 validation is shown for a cloudless sky day, the 20 April 2007, whereas in Figures 7 and 8 validation is presented for a day with an entirely overcast sky, the 22 January 2007.
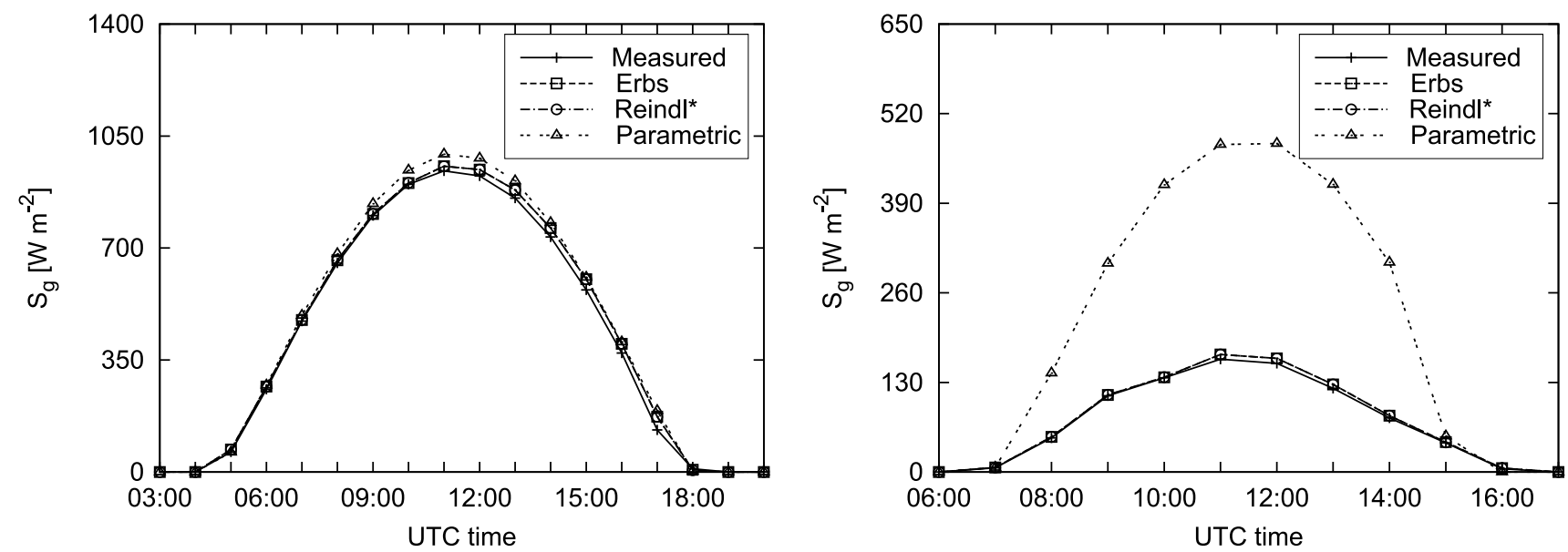

Figure 6. Same as in Figure 5 but for global radiation $S_{\mathrm{g}}$.

Figure 8. Same as in Figure 7 but for global radiation $S_{\mathrm{g}}$. 
[34] In Figure 5a measured total diffuse radiation $S_{\mathrm{d}}+S_{\mathrm{t}}$ is compared to modeled diffuse sky radiation values $S_{\mathrm{d}}$ with the decomposition model of Erbs et al. [1982] and with our Reindl* model (cf. equations (4), (5), (7)). $S_{\mathrm{d}}$ was also modeled with the parametric model as described by equation (4). Even though only direct and diffuse sky radiation is validated here, we depict modeled terrain reflected radiation $S_{\mathrm{t}}$ based on $S_{\mathrm{b}}$ and $S_{\mathrm{d}}$ computed with the Reindl* model to illustrate the size of $S_{\mathrm{t}}$ at Weissfluhjoch study site. Most of the time, all computed diffuse sky radiation values overestimate measured total diffuse radiation. The largest differences were with the model of Erbs et al. [1982], with a maximum difference of about $56 \mathrm{~W} \mathrm{~m}^{-2}$ at 11 UTC. The best fit is with the radiation values obtained from the parametric model with a maximum difference of about $18 \mathrm{~W} \mathrm{~m}^{-2}$ at 9 UTC. The diffuse sky radiation of both decomposition models underestimates the total diffuse radiation at 5 and 6 UTC whereas the parametric model agrees very well with measurements at these times. We point out that we only compared modeled diffuse sky radiation to measured total diffuse radiation since we aimed for a validation of diffuse sky radiation values and diffuse sky radiation was not measured at Weissfluhjoch study site. However, as shown in Figure 5a the modeled diffuse sky radiation overestimated measured total diffuse radiation.

[35] In Figure 5b the same comparison is shown for direct radiation $S_{\mathrm{b}}$. Since the measured diffuse sky radiation was mainly overestimated by both decomposition models, the one of Erbs et al. [1982] and the Reindl* model, the direct radiation is mainly underestimated. The largest differences are for the model of Erbs et al. [1982] with a maximum difference of about $65 \mathrm{~W} \mathrm{~m}^{-2}$ at 10 UTC. Direct radiation values obtained from the parametric model mostly overestimate the measured values. The maximum difference was about $50 \mathrm{~W} \mathrm{~m}^{-2}$ at 17 UTC.

[36] In Figure 6 the comparison is shown for global radiation $S_{\mathrm{g}}$. Summing up total diffuse and direct radiation leads to good agreement of modeled and measured values. The largest differences were for the parametric model with about $55 \mathrm{~W} \mathrm{~m}^{-2}$ at $12 \mathrm{UTC}$. A better agreement was obtained when the parameterized radiation components were adjusted for the actual atmospheric conditions obtained from a decomposition model. For the model of Erbs et al. [1982] as well as for the Reindl* model the maximum differences were about $33 \mathrm{~W} \mathrm{~m}^{-2}$ at $15 \mathrm{UTC}$.

[37] Overall, the parametric model agreed best with measurements for the individual radiation components which is because the 20 April 2007 was a day with cloudless sky where broadband atmospheric transmittances are sufficient to compute incident radiation. However, in the presence of clouds or high humidity this does not hold which is demonstrated by the same validation as described for Figure 5 and 6 but on an entirely overcast day.

[38] As shown in Figure 7a, now, most of the time, all computed diffuse sky radiation values underestimate measured total diffuse radiation. The largest differences were with the parametric model, with a maximum difference of about $87 \mathrm{~W} \mathrm{~m}^{-2}$ at 12 UTC. On this day with overcast sky both decomposition models agree very well with measured total diffuse radiation. Small differences occur between 9 and 12 UTC with a maximum difference of about $12 \mathrm{~W} \mathrm{~m}^{-2}$ at 9 UTC for the Reindl* model. Regarding the decomposition models, the modeled terrain reflected radiation $S_{\mathrm{t}}$ does almost account for the difference between measured total diffuse radiation and modeled diffuse sky radiation. The maximum terrain reflected radiation is of about $5 \mathrm{~W} \mathrm{~m}^{-2}$ at 11 UTC.

[39] As shown in Figure 7b, according to the overall underestimation of measured total diffuse radiation values, measured direct radiation is overestimated. However, only small overestimations were obtained for the decomposition models with a maximum difference of about $13 \mathrm{~W} \mathrm{~m}^{-2}$ at 11 UTC for the Reindl* model. As for diffuse sky radiation the largest differences were for the parametric model with a maximum difference of about $374 \mathrm{~W} \mathrm{~m}^{-2}$ at 12 UTC.

[40] In Figure 8 the same comparison is shown as in Figure 6 but for 22 January 2007. The largest differences were for the parametric model with about $319 \mathrm{~W} \mathrm{~m}^{-2}$ at 12 UTC. Again, a much better agreement was obtained when the parameterized radiation components were adjusted for the actual atmospheric conditions obtained from a decomposition model. For the model of Erbs et al. [1982] as well as for the Reindl* model the maximum differences were about $7 \mathrm{~W} \mathrm{~m}^{-2}$ at 12 UTC.

\subsubsection{Terrain Reflected Radiation}

[41] For our validation of modeled terrain reflected radiation we only present validations on days with cloudless sky since otherwise it is difficult to separate radiation reflected by clouds by that from terrain. In Figure 9a the two minutes measurements of global radiation, with and without terrain influence, are compared to modeled global radiation values with and without terrain reflected radiation for a winter day, the 20 April 2007. The relative differences of measured terrain reflected radiation values and modeled terrain reflected radiation values are reproduced very well. Maximum terrain reflected radiation $S_{\mathrm{t}}$ of about $20 \mathrm{~W} \mathrm{~m}^{-2}$ at $11 \mathrm{UTC}$ was measured and is modeled perfectly (less than $1 \mathrm{~W} \mathrm{~m}^{-2}$ difference). Note that, a visible terrain fraction of only about $3 \%$ at the measurement site provides considerable terrain reflected radiation of $20 \mathrm{~W} \mathrm{~m}^{-2}$. Small differences at other time steps likely come from errors in the measurement setup, variations due to the chosen time average interval to model radiation values and due to the fact that two minute measurements are compared to hourly modeled values.

[42] To check if modeled terrain reflected radiation can be obtained by an additional diffuse sky fraction according to the terrain fraction of $3 \%$ we made a rough calculation. We computed $S_{\mathrm{t}}$ by $S_{\mathrm{d}} 0.03$ from the modeled diffuse sky radiation obtained at $11 \mathrm{UTC}$ and compared this to the measured terrain reflected radiation value $S_{\mathrm{t}}$ at 11 UTC. Measured $S_{\mathrm{t}}$ was underestimated by about $16 \mathrm{~W} \mathrm{~m}^{-2}$ which demonstrates that multiple terrain reflections cannot accurately be computed by only accounting for diffuse sky radiation.

[43] Figure 9b shows results for a summer day, the 24 September 2007. All measured and modeled radiation values lie approximately on top of each other. Terrain reflected radiation of only $3 \mathrm{~W} \mathrm{~m}^{-2}$ was measured. The small values clearly demonstrate that the modeled values are almost within the accuracy of the measurement device for a summer day and also show the importance of (terrain) reflected radiation for snow covered terrain.

[44] Even though the terrain view factor (visible terrain fraction) at the long hut at Weissfluhjoch study site represents about only $3 \%$, Figure 9 clearly demonstrates that 
a)

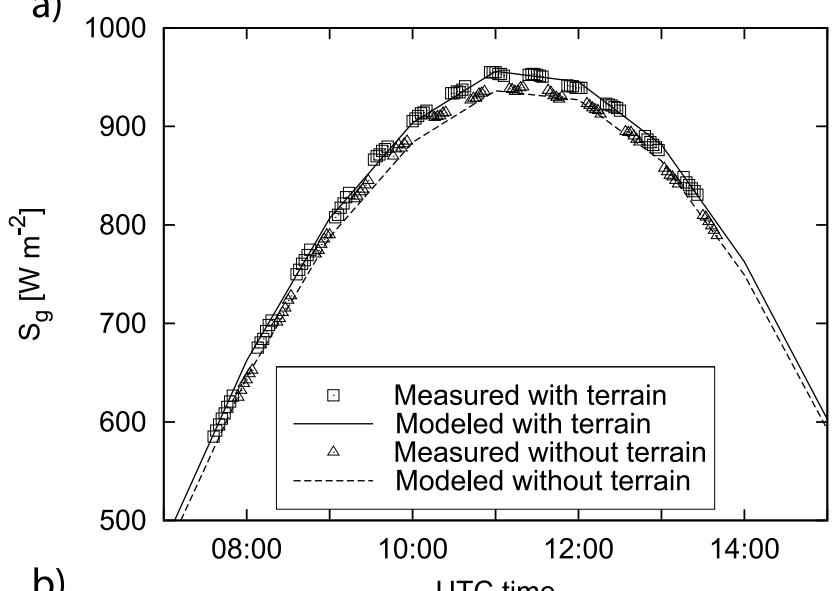

b)

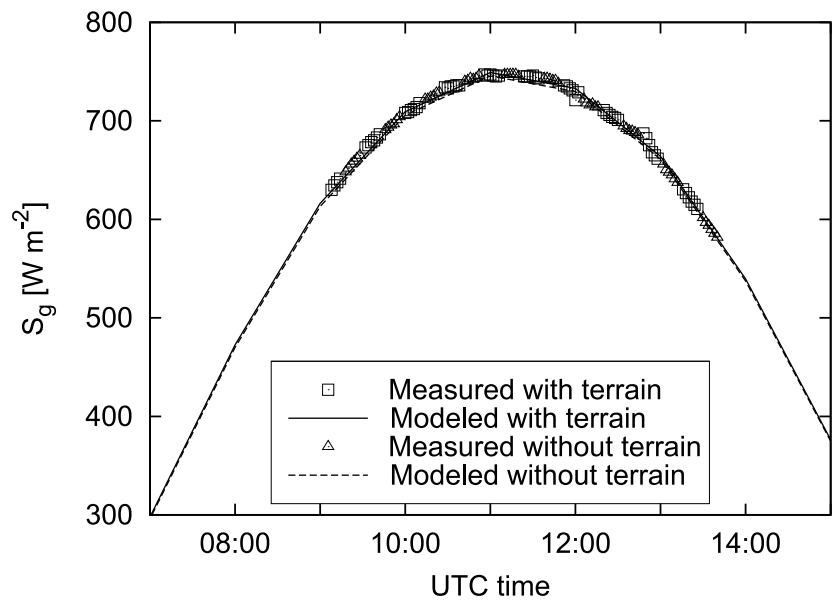

Figure 9. Comparison of global radiation measurements to modeled values at Weissfluhjoch study site with $S_{\mathrm{g}}$ measured and modeled masked (without terrain) and measured and modeled unmasked (with terrain) for (a) the 20 April 2007 and (b) the 24 September 2007. In fact only the unfilled symbols represent a modeled hourly value. However, the lines in-between may be regarded as a reasonable interpolation.

for a specific surface patch the measured terrain reflected radiation is captured very well by the radiosity approach. This could be reproduced for a representative winter day with large mean surface albedos as well as for a summer day with low mean surface albedos.

\subsection{Validation With a Model: Monte Carlo Model MYSTIC}

[45] We present validations of modeled radiation components with those obtained from MYSTIC on a day with cloudless sky. A comparison for a cloudy day would be possible in principle; however, in order to account for diurnal variations of clouds, MYSTIC requires detailed cloud information which was not recorded at the Weissfluhjoch study site.

[46] In Figure 10a modeled values of total diffuse radiation $S_{\mathrm{d}}+S_{\mathrm{t}}$ are compared for 20 April 2007 at the Weissfluhjoch study site. Total diffuse radiation was computed in two ways with the radiosity model: (1) $S_{\mathrm{b}}$ and $S_{\mathrm{d}}$ were derived with equations (3)-(7), called Radiosity (Reindl*) model, and (2)
$S_{\mathrm{b}}$ and $S_{\mathrm{d}}$ were derived with the parametric model, i.e., equations (3) and (4), called Radiosity (Parametric) model. Hourly radiation values computed with the Radiosity model are compared to half-hourly radiation values computed with MYSTIC. The agreement between the Radiosity (Parametric) model and the MYSTIC model is very good. MYSTIC computes slightly larger values during midday and slightly lower ones in the morning and afternoon. Maximum differences are only about $6 \mathrm{~W} \mathrm{~m}^{-2}$ at $11 \mathrm{UTC}$. The agreement was poorer between the Radiosity (Reindl*) model and MYSTIC, with maximum differences of about $30 \mathrm{~W} \mathrm{~m}^{-2}$ at 6 UTC.

[47] In Figure 10b direct radiation is compared. Again, there was better agreement between the Radiosity (Parametric) model and the MYSTIC model, with maximum differences of about $30 \mathrm{~W} \mathrm{~m}^{-2}$ at 11 UTC. As for the total diffuse radiation, a poorer agreement is obtained for direct radiation between the Radiosity (Reindl*) model and
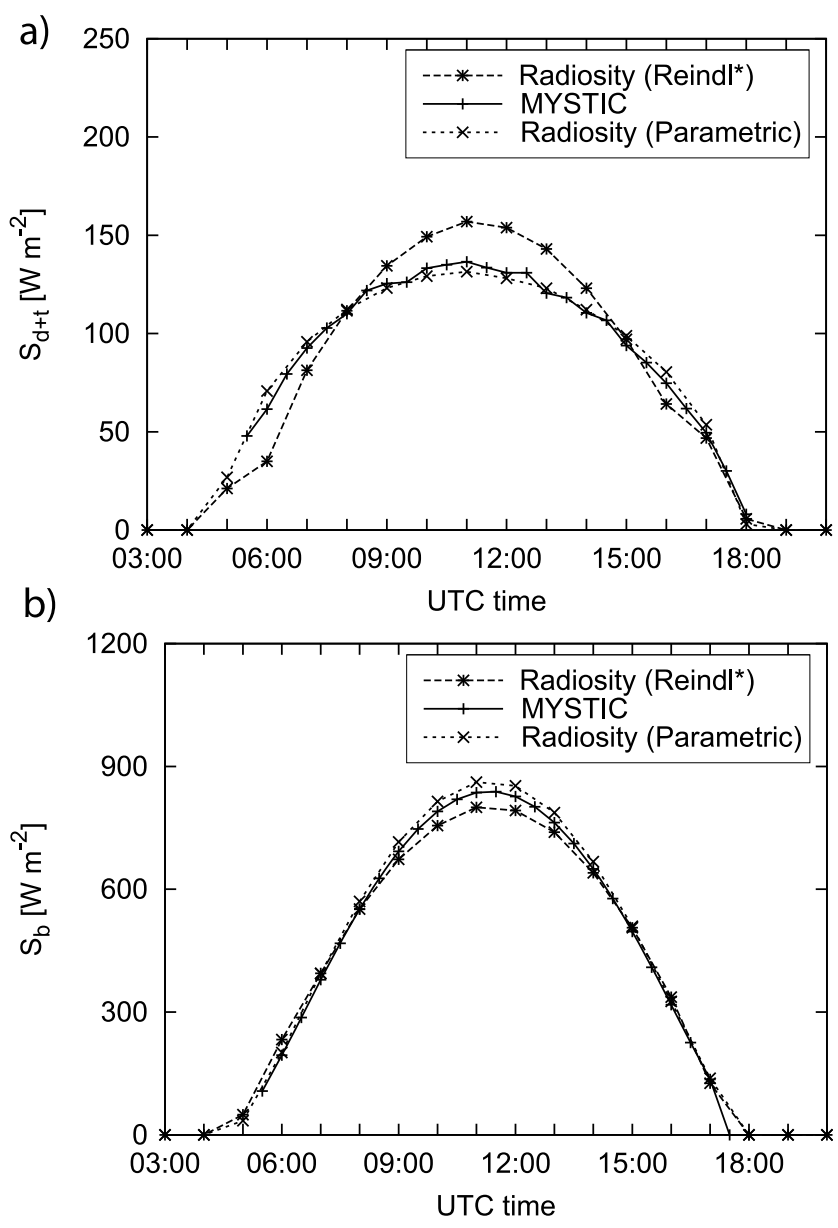

Figure 10. Comparison of modeled radiation on 20 April 2007 at Weissfluhjoch study site: (a) total diffuse radiation $S_{\mathrm{d}}+S_{\mathrm{t}}$ and (b) direct radiation $S_{\mathrm{b}}$. Modeled values of the radiosity approach, implemented in the surface radiation balance model, and the MC model MYSTIC are compared. Plus signs indicate that radiation components are derived with the MYSTIC model, stars indicate the Reindl* model (Radiosity $($ Reindl*)), and crosses indicate that they are computed with the parametric model (Radiosity (Parametric)) (see Figure 5). 
MYSTIC, with maximum deviations of about $40 \mathrm{~W} \mathrm{~m}^{-2}$ at 11 UTC.

[48] The surface radiation balance model, which includes multiple terrain reflected radiation by using the radiosity approach, agrees well with the three-dimensional cloudy radiative transfer model MYSTIC. The comparison was conducted for a cloudless sky day, thus little cloud backscattering occurred, which might have led to larger deviations between both models. The bad agreement when using the Radiosity (Reindl*) model stems from the decomposition model and is not due to the radiosity approach. This corresponds to the results obtained independently in Figure 5 and Figure 7.

\section{Discussion and Conclusions}

[49] We presented a validation of a surface radiation balance model for complex terrain where high albedos occur and which can be driven from a single set of meteorological surface parameters and a single, exposed measurement of global radiation. The model computes spatial direct and diffuse sky radiation for cloudless sky by applying a parametric model, which is mainly based on work by Bird and Hulstrom [1980, 1981]. One direct and diffuse sky radiation value under all sky conditions is obtained by means of decomposing a measured global radiation value at an exposed measurement site. For this a combination of two decomposition models of Reindl et al. [1990] is used. In order to obtain spatial direct and diffuse sky radiation values under all atmospheric conditions (including cloudy sky), the spatial radiation components computed for cloudless sky are adjusted by coefficients based on the actual atmospheric conditions obtained from the new decomposition model (this model is called Reindl* model) at the exposed measurement site. Furthermore, we compute multiple, anisotropic terrain reflected radiation with the radiosity approach, which was presented by Helbig et al. [2009]. The radiation balance model is a module of Alpine3D, a modular model system for alpine surface processes (overview in the work of Lehning et al. [2004]). Surface characteristics (snow cover, albedo, etc.) were obtained from the SNOWPACK module in Alpine3D. Validations of each individual radiation model component with high-quality point measurements at Weissfluhjoch study site in Davos (Switzerland) were presented in order to make it possible to assess sources of errors. In order to assess the accuracy of our surface radiation balance model, radiation components were also compared to those obtained with a more sophisticated radiation model for a cloudy atmosphere.

[50] Especially in complex terrain and in model domains with high resolutions, shading has a dominant influence on incident SW radiation. We estimated the accuracy of our Sun-or-shadow algorithm to determine the horizon line by comparing modeled horizon angles with horizon angles derived from tachymeter measurements as well as with horizon angles obtained by digital image analysis from a panorama picture of "Atlas der Schweiz" (Figure 3, bottom). Since the same DEM of $25 \mathrm{~m}$ is used for visualization in "Atlas der Schweiz" as for our modeling, both horizon lines agreed very well (maximum error of approximately one degree; Root Mean Square Error (RMSE) $0.43^{\circ}$ ). Some differences might arise from the digital image analysis process, the difference between the terrain parameters retrieval method from the DEM in the model as opposed to the visual interpolation method in "Atlas der Schweiz," or from inaccuracies in the visibility detection algorithm. Overall the scanned horizon angles proved to match the angles of both other methods well (RMSE of Sun-or-shadow algorithm $0.99^{\circ}$ and RMSE of digital image analysis $0.97^{\circ}$ ). The largest differences, up to $2.5^{\circ}$, were most likely due to the fact that steep ridges are flattened in the DEM with horizontal grid cell resolutions of $25 \mathrm{~m}$. However, we point out that a $2.5^{\circ}$ horizon angle error is minor considering an hourly time step, corresponding to a mean Sun hour angle change of $15^{\circ}$ per hour. This demonstrates that there is a lower limit to the model time step, which should only be decreased if horizontal grid cell resolutions of the DEM are adjusted accordingly. In addition, the Sun azimuth angle is fixed during a model time step although in reality the position of the Sun, and consequently the Sun-or-shadow value, varies within that time step. Therefore, our Sun-or-shadow algorithm determines the horizon line accurately, i.e., within the limit of the underlying DEM using square horizontal grid cells. An accurate implementation of shading (Sun-or-shadow) is a prerequisite for a precise computation of radiation components in complex terrain.

[51] High-quality permanent measurements of direct and diffuse sky radiation were used to validate modeled values for two days with opposite sky conditions: namely cloudless and overcast sky. We compared measured radiation values to modeled values with the parametric model, based on mean integrated atmospheric transmittances as well as on a set of meteorological surface parameters. Further, we compared measured values to values modeled with the parametric model that were adjusted with different decomposition models [Erbs et al., 1982; Reindl et al., 1990]. For the day with cloudless sky conditions we found the best agreement with measurements for modeled radiation components with only the parametric model (RMSE of direct and total diffuse radiation, respectively, $19 \mathrm{~W} \mathrm{~m}^{-2}, 27 \mathrm{~W} \mathrm{~m}^{-2}$ compared to Reindl* $31 \mathrm{~W} \mathrm{~m}^{-2}, 36 \mathrm{~W} \mathrm{~m}^{-2}$ and model of Erbs et al. [1982] $39 \mathrm{~W} \mathrm{~m}^{-2}, 47 \mathrm{~W} \mathrm{~m}^{-2}$; see Figure 5). This is not surprising, since our tested decomposition models were not based on data of the climate of our study site. The combination of two models of Reindl et al. [1990] for the Eastern Swiss Alps showed the best agreement with measurement data of direct and total diffuse radiation. In contrast, for the day with overcast sky conditions we found by far the best agreement with measurements for modeled radiation components when parameterized radiation components are adjusted with actual atmospheric conditions obtained from the decomposition model (RMSE of direct and total diffuse radiation, respectively: Reindl* $7 \mathrm{~W} \mathrm{~m}^{-2}, 4 \mathrm{~W} \mathrm{~m}^{-2}$, model of Erbs et al. [1982] $5 \mathrm{~W} \mathrm{~m}^{-2}, 3 \mathrm{~W} \mathrm{~m}^{-2}$ and parametric model $243 \mathrm{~W} \mathrm{~m}^{-2}$, $32 \mathrm{~W} \mathrm{~m}^{-2}$; see Figure 7). This again is not surprising, since the parametric model cannot picture an atmospheric transmittance for cloudy sky conditions by means of a parameterized mean atmospheric transmittance simply altered by a set of meteorological surface parameters. From the validation presented in Figure 7 it becomes clear that the parametric model alone cannot be used to describe individual radiation components in the presence of clouds (mean RMSE for both radiation components $138 \mathrm{~W} \mathrm{~m}^{-2}$ ). We therefore apply a decomposition model in Alpine3D to cope with a variety of weather conditions although due to a lack of precise mea- 
surements this has not been validated so far for all cloudy sky conditions, i.e., cloud cover fractions of $1 / 8$ to $7 / 8$. Overall, for both tested sky conditions our proposed decomposition model Reindl* provided a slightly better agreement with measurements than the model of Erbs et al. [1982] (mean RMSE for both sky conditions and both, direct and total diffuse radiation: Reindl* $20 \mathrm{~W} \mathrm{~m}^{-2}$, model of Erbs et al. [1982] $24 \mathrm{~W} \mathrm{~m}^{-2}$ ). We also compared modeled and measured global radiation values, i.e., the sum of direct, diffuse sky and terrain reflected radiation. For both sky conditions the best agreement was obtained when parameterized radiation components are adjusted with actual atmospheric conditions obtained from the decomposition models (RMSE for both sky conditions: Reindl* as well as model of Erbs et al. [1982] $13 \mathrm{~W} \mathrm{~m}^{-2}$ and parametric model $128 \mathrm{~W} \mathrm{~m}^{-2}$; see Figures 6 and 8). This result emphasizes the importance of evaluating individual radiation components rather than global radiation values only. Good agreements in global radiation values do not a priori indicate that individual radiation components are correctly computed. Note that errors in radiation components can introduce errors in the computation of incident radiation in complex terrain.

[52] A simple new measurement setup was designed to validate our modeled terrain reflected radiation. For this, a removable horizon was constructed around a pyranometer (Figure 4). A terrain view factor (visible terrain fraction) of about $3 \%$ resulted in measured relative values of terrain reflected radiation of about $20 \mathrm{~W} \mathrm{~m}^{-2}$ for a winter day with high albedos and of about $3 \mathrm{~W} \mathrm{~m}^{-2}$ for a summer day with low albedos (Figure 9). Modeled and measured global radiation values agreed very well for both days. We compared the terrain reflected radiation to a more simple approach where terrain reflected radiation is taken as the amount of diffuse sky radiation described by the visible terrain fraction. This revealed an underestimation of the measured terrain reflected radiation value of about $16 \mathrm{~W} \mathrm{~m}^{-2}$. It is likely that this difference will increase with more multiple terrain reflections.

[53] The sophisticated three-dimensional Monte Carlo radiative transfer model MYSTIC, accounting for cloudy atmospheres and well validated, was used to validate our individual radiation components. Since this model also accounts for terrain influence, this comparison allowed for another independent validation. We found very good agreement for total diffuse (diffuse sky plus terrain reflected) radiation at the study site when incident radiation was computed with the parametric model (maximum difference of about $6 \mathrm{~W} \mathrm{~m}^{-2}$; Figure 10a). The agreement was poorer but still reasonable for direct radiation (maximum difference of about $30 \mathrm{~W} \mathrm{~m}^{-2}$; Figure $10 \mathrm{~b}$ ). When using our decomposition model Reindl* (combination of models of Reindl et al. [1990]), we still found reasonable agreements for both components (maximum deviation of about $30-40 \mathrm{~W} \mathrm{~m}^{-2}$; Figures 10a and 10b). This further validates the modeled SW radiation components values of our surface radiation model for a cloudless sky day.

[54] Even though the model is developed to be applicable to cloudy sky conditions, here we only presented validations with measurements for cloudless sky and overcast sky conditions. However, we point out that our detailed point validation for cloudless sky provides a valuable starting point for further individual model improvements such as a suitable decomposition model. Furthermore, we believe it gives some insight in problems related to the computation of surface characteristics such as soil or snowpack temperatures in complex terrain. Thanks to our simple measurement setup the point measurements can easily be duplicated and would provide a possibility to simultaneously measure terrain reflected radiation at various sites.

[55] Acknowledgments. We gratefully acknowledge the anonymous referees for their useful suggestions. We thank Charles Fierz for his advices regarding radiation measurements and Roland Meister as well as Patrick Thee for their assistance with the tachymeter measurements. This work was cofinanced by the Confederation's innovation promotion agency (project 7723.1 ESPP-ES) and by the European Commission via AWARE.

\section{References}

Amanatides, J., and A. Woo (1987), A fast voxel traversal algorithm for ray tracing, in Eurographics '87, edited by G. Marechal, p. 3-10, Elsevier, Amsterdam, Netherlands.

Anderson, G. P., S. A. Clough, F. X. Kneizys, J. H. Chetwynd, and E. P. Shettle (1986), AFGL Atmospheric Constituent Profiles $(0-120 \mathrm{~km})$, Tech. Rep. AFGL-TR-86-0110, AFGL, Hanscom AFB, Mass.

Bartelt, P., and M. Lehning (2002), A physical SNOWPACK model for the Swiss avalanche warning: Part I. Numerical model, Cold. Reg. Sci. Technol., $35,123-145$.

Bintanja, R. (1996), The parameterization of shortwave and longwave radiative fluxes for use in zonally averaged climate models, J. Clim., 9, 439-454.

Bird, R. E., and R. L. Hulstrom (1980), Direct insolation models, Tech. Rep. SERI/TR-335-344,Sol. Energy Res. Inst., Golden, Colo.

Bird, R. E., and R. L. Hulstrom (1981), A simplified clear sky model for direct and diffuse insolation on horizontal surfaces, Tech. Rep. SERI TR-642-761, Sol. Energy Res. Inst., Golden, Colo.

Boland, J., L. Scott, and M. Luther (2001), Modelling the diffuse fraction of global solar radiation on a horizontal surface, Environmetrics, 12 , 103-116.

Cahalan, R. F., et al. (2005), The International Intercomparison of 3D Radiation Codes (I3RC): Bringing together the most advanced radiative transfer tools for cloudy atmospheres, Bull. Am. Meteorol. Soc., 86(9), 1275-1293.

Corripio, J. G. (2002), Modelling the energy balance of high altitude glacerised basins in the central Andes, Ph.D. thesis, Univ. of Edinburgh, Edinburgh, U. K.

Dozier, J., and J. Bruno (1981), A faster solution to the horizon problem, Comput. Geosci., 7, 145-151.

Emde, C., and B. Mayer (2007), Simulation of solar radiation during a total eclipse: A challenge for radiative transfer, Atmos. Chem. Phys., 7, 2259-2270.

Erbs, D. G., S. A. Klein, and J. A. Duffie (1982), Estimation of the diffuse radiation fraction for hourly, daily and monthly-average global radiation, Sol. Energy, 28, 293-302.

Fröhlich, C. (2006), Solar irradiance variability since 1978, Space Sci. Rev., $125,53-65$.

Fröhlich, C., and J. Lean (1998), The Sun's total irradiance: Cycles, trends and related climate change uncertainties since 1976, Geophys. Res. Lett., 25(23), 4377-4380, doi:10.1029/1998GL900157.

Gueymard, C. A., and D. R. Myers (2008), Validation and ranking methodologies for solar radiation models, in Modeling Solar Radiation at the Earth's Surface, edited by V. Badescu, pp. 479-510, Springer, Berlin.

Helbig, N. (2009), Application of the radiosity approach to the radiation balance in complex terrain, Ph.D. thesis, Univ. of Zurich, Zurich, Switzerland.

Helbig, N., H. Löwe, and M. Lehning (2009), Radiosity approach for the surface radiation balance in complex terrain, J. Atmos. Sci., 66, 2900-2912, doi:10.1175/2009JAS2940.1.

Iqbal, M. (1983), An Introduction to Solar Radiation, 390 pp., Academic, San Diego, Calif.

Kato, S., T. P. Ackerman, J. H. Mather, and E. E. Clothiaux (1999), The $\mathrm{k}$-distribution method and correlated $\mathrm{k}$ approximation for a shortwave radiative transfer model, J. Quant. Spectrosc. Radiat. Transfer, 62, 109-121.

Lehning, M., P. Bartelt, B. Brown, C. Fierz, and P. Satyawali (2002a), A physical SNOWPACK model for the Swiss avalanche warning: Part II. Snow microstructure, Cold. Reg. Sci. Technol., 35, 147-167.

Lehning, M., P. Bartelt, B. Brown, and C. Fierz (2002b), A physical SNOWPACK model for the Swiss avalanche warning: Part III. Meteoro- 
logical forcing, thin layer formation and evaluation, Cold. Reg. Sci. Technol., 35, 169-184.

Lehning, M., et al. (2004), Review of SNOWPACK and ALPINE3D applications, in 5th International Snow Engineering Conference, Davos, Switzerland, edited by Bartelt et al., pp. 299-307, A. A. Balkema, Brookfield, Vt.

Lehning, M., I. Völksch, D. Gustafsson, T. Nguyen, and M. Stähli (2006), ALPINE3D: A detailed model of mountain surface processes and its application to snow hydrology, Hydrol. Processes, 20, 2111-2128.

Liu, B. Y. H., and R. C. Jordan (1960), The interrelationship and characteristic distribution of direct, diffuse and total solar radiation, Sol. Energy, 4, $1-19$.

Mayer, B. (2009), Radiative transfer in the cloudy atmosphere, Eur. Phys. J. Conf., 1, 75-99.

Mayer, B., S. Hoch, and C. D. Whiteman (2010), Validating the MYSTIC three-dimensional radiative transfer model with observations from the complex topography of Arizona's Meteor Crater, Atmos. Chem. Phys. Discuss., 10, 13,373-13,405.
Nunez, M. (1980), The calculation of solar and net radiation in mountainous terrain, J. Biogeogr., 7(2), 173-186.

Orgill, J. F., and K. G. Hollands (1977), Correlation equation for hourly diffuse radiation on a horizontal surface, Sol. Energy, 19, 357-359.

Reindl, D. T., W. A. Beckman, and J. A. Duffie (1990), Diffuse fraction correlations, Sol. Energy, 45, 1-7.

Shettle, E. P. (1989), Models of aerosols, clouds and precipitation for atmospheric propagation studies, paper presented at Atmospheric Propagation in the UV, Visible, IR and mm-Region and Related System Aspects, AGARD, Neuilly sur Seine, France

Spencer, J. W. (1971), Fourier series representation of the position of the Sun, Search, 2, 172.

N. Helbig, L. Lehning, and H. Löwe, WSL Institute for Snow and Avalanche Research SLF, Flüelastr 11, CH-7260 Davos, Switzerland. (norahelbig@gmail.com)

B. Mayer, Meteorological Institute, Ludwig-Maximilians University, Theresienstrasse 37, D-80333 München, Germany. 